OPEN ACCESS

Edited by:

Christoph Bührer,

Charité Universitätsmedizin Berlin,

Germany

Reviewed by:

Joseph Ting,

University of British Columbia,

Canada

Giovanni Vento,

Università Cattolica del

Sacro Cuore, Italy

*Correspondence:

Eugene M. Dempsey

g.dempsey@ucc.ie

Specialty section:

This article was submitted to

Neonatology,

a section of the journal

Frontiers in Pediatrics

Received: 16 January 2018

Accepted: 20 March 2018

Published: 06 April 2018

Citation:

Garvey $A A$, Kooi EMW and

Dempsey EM (2018) Inotropes for Preterm Infants: 50 Years

on Are We Any Wiser?

Front. Pediatr. 6:88.

doi: 10.3389/fped.2018.00088

\section{Inotropes for Preterm Infants: 50 Years on Are We Any Wiser?}

\author{
Aisling A. Garvey ${ }^{1,2}$, Elisabeth M. W. Kooi ${ }^{1,3}$ and Eugene M. Dempsey ${ }^{1,2 *}$ \\ ${ }^{1}$ Department of Paediatrics and Child Health, Neonatal Intensive Care Unit, University College Cork, Cork, Ireland, ${ }^{2}$ INFANT, \\ Irish Centre for Fetal and Neonatal Translational Research, University College Cork, Cork, Ireland, ${ }^{3}$ Division of Neonatology, \\ Beatrix Children's Hospital, University Medical Center Groningen, University of Groningen, Groningen, Netherlands
}

For almost half a century, inotropes have been administered to preterm infants with the ultimate goal of increasing their blood pressure. A number of trials, the majority of which focused on dopamine administration, have demonstrated increased blood pressure following inotrope administration in preterm infants and have led to continued use of inotropes in our neonatal units. We have also seen an increase in the number of potential agents available to the clinician. However, we now know that hypotension is a much broader concept than blood pressure alone, and our aim should instead be focused on improving end organ perfusion, specifically cerebral perfusion. Only a limited number of studies have incorporated the organ-relevant hemodynamic changes and long-term outcomes when assessing inotropic effects in neonates, the majority of which are observational studies or have a small sample size. In addition, important considerations, including the developing/maturing adrenergic receptors, polymorphisms of these receptors, and other differences in the pharmacokinetics and pharmacodynamics of preterm infants, are only recently being recognized. Certainly, there remains huge variation in practice. The lack of well-conducted randomized controlled trials addressing these relevant outcomes, along with the difficulty executing such RCTs, leaves us with more questions than answers. This review provides an overview of the various inotropic agents currently being used in the care of preterm infants, with a particular focus on their organ/cerebral hemodynamic effects both during and after transition.

Keywords: neonatology, hypotension, inotropes, preterm infants, blood pressure, end organ perfusion

\section{INTRODUCTION}

For almost half a century, inotropes have been administered to preterm infants with the ultimate goal of increasing mean arterial blood pressure (MBP). A number of trials, the majority of which focused on dopamine, have demonstrated increased MBP following inotrope administration in preterm infants. We have recently seen an increase in the number of potential inotropic agents available to the clinician with tailored therapeutic regimes advocated (1).

Continued reliance on MBP to initiate therapy and guide response remains the norm (2). However, hypotension is a much broader concept. A limited number of studies have incorporated organ-relevant hemodynamic changes and long-term outcomes when assessing inotropic effects, the majority of which are observational studies or have been limited by small sample size. In addition, important considerations including the maturing adrenergic receptors, polymorphisms, and other 
differences in the pharmacokinetics and pharmacodynamics of preterm infants are only recently being considered (3).

The lack of well-conducted RCTs addressing relevant outcomes, along with the difficulty in executing such trials (4), leaves us with more questions than answers. This review provides an overview of the various inotropic agents currently being used in the care of preterm infants, with a particular focus on hemodynamic effects, challenges in safe administration and why it is difficult to conduct RCTs in this area.

\section{DOPAMINE AND DOBUTAMINE}

Few large RCTs have been performed investigating the effect of dopamine and/or dobutamine in preterm infants with hypotension or signs of low organ perfusion, but numerous observational studies and reviews have been published (5-7).

Dopamine is the most studied inotrope in preterm infants. It increases MBP (8-10) through its inotropic and vasopressor qualities. Dopamine is the direct precursor of noradrenaline (NA). It positively stimulates the $\alpha$ - and $\beta$-adrenoceptors, inducing both vascular smooth muscle and heart muscle contraction. The effects on cardiac output (CO) and end organ flow remain largely unanswered but are probably dose specific, with higher doses potentially inducing a significant increase in SVR which may attenuate its positive inotropic effect, highlighting the potential inotrope/afterload imbalance associated with some inotropes $(8,11)$. Dopamine administration not only results in increased serum dopamine levels but also in NA and epinephrine levels $(12,13)$. In these infants, endogenous catecholamine levels may already be high after birth (14).

Dobutamine is a synthetic catecholamine, stimulating $\beta 1$ receptors, increasing $\mathrm{CO}$, and reducing smooth muscle contraction resulting in peripheral vasodilation and a lower MBP increase when compared with dopamine $(9,10)$. It has been suggested as an alternative to dopamine; however, the different mechanisms of action might make it more suitable for certain disease states in the preterm infant.

Various parameters have been studied for the assessment of end organ blood flow. CO, mainly left ventricular output (LVO), has been described in a number of trials. A meta-analysis (15) comparing dopamine to dobutamine in hypotensive preterm infants concluded that dopamine led to a greater increase in MBP, whereas dobutamine had a greater effect on LVO. Clinically relevant outcomes such as IVH, PVL, or mortality were no different. An RCT including 41 preterm infants with low SVC flow $(<41 \mathrm{ml} / \mathrm{kg} / \mathrm{min})$ were randomized to either dopamine or dobutamine after receiving a volume bolus. The results showed that although dobutamine resulted in a lower MBP, it had a significantly larger increase in SVC flow than dopamine (mean, +9.9 versus $-3.2 \mathrm{ml} / \mathrm{kg} / \mathrm{min}$, $P=0.02) .40 \%$ failed to increase/maintain SVC flow in response to either agent and no differences in mortality or morbidity were found (16). More recently Bravo et al. randomized 28 preterm infants with low SVC to either dobutamine or placebo (17). The majority of infants achieved and maintained an SVC flow $\geq 41 \mathrm{ml} /$ $\mathrm{kg} / \mathrm{min}$ after intervention and infants treated with dobutamine $(n=16)$ showed a higher heart rate (HR) and improved base excess compared with those treated with placebo $(n=12)$.
Two studies have assessed the effect on surrogate markers of cerebral blood flow. Using xenon techniques, Lundstrøm et al. found dopamine administered at $5 \mu \mathrm{g} / \mathrm{kg} / \mathrm{min}$ resulted in increased BP and LVO, but no change in cerebral blood flow, in preterm infants with an MBP between 29 and $40 \mathrm{mmHg}$ (18). This would suggest that dopamine results in a degree of vasoconstriction, either directly from its effect on cerebral vasculature or from a compensatory autoregulatory effect from the increase in systemic BP. This lack of increased cerebral perfusion was also suggested from fetal sheep studies where the dopamine-induced increased BP resulted in a cerebral autoregulatory $\alpha$-adrenergic vasoconstrictive response, maintaining cerebral blood flow (19). However, in a subsequent RCT comparing dopamine versus epinephrine in preterm infants with low BP, Pellicer and colleagues measured the effects on cerebral oxygenation as a surrogate for cerebral perfusion (20). They found no difference in the increase in cerebral oxygenation, suggesting an increase in cerebral perfusion from both drugs.

While there are few RCTs addressing end organ perfusion there are numerous observational studies reporting effects including right ventricular output (RVO), LVO, pulmonary pressures, and cerebral blood flow. One report on the effect of dopamine on right ventricular performance included hypotensive preterm neonates in whom right ventricular end systolic volume decreased approximately $30 \%$, whereas right ventricular end diastolic volume did not change. Ejection fraction therefore increased and RVO increased from 90 to $112 \mathrm{ml} / \mathrm{kg} / \mathrm{min}$ (21). Specifically in preterm infants with septic shock, in whom either dopamine or dobutamine was commenced, RVO and HR increased, but LVO and organ flow did not. After analyzing subgroups, both drugs did not seem to significantly increase both LVO and RVO. The increase in HR was mainly seen after dopamine infusion (22). The effect on pulmonary artery pressure was described by Liet et al. in 19 preterm ventilated infants ( $4 \pm 3$ days of life), with a patent ductus arteriosus (PDA), showing an overall increase in arterial pulmonary pressure following dopamine administration (23).

Seri et al. found an increased BP and urinary output in preterm infants ( $<2$ days) following dopamine administration, but no change in mesenteric and cerebral perfusion indices (24). Contradictive results have been reported on the effect of dopamine on cerebrovascular autoregulation in infants. Wong et al. found an increased potential for cerebral flow and metabolism coupling, suggesting an improved blood supply in response to demand (25). Contrary to these findings, Eriksen et al. found dopamine had an adverse effect on cerebrovascular autoregulation in preterm infants (26). A meta-analysis of predominantly observational studies investigating the effect of dopamine showed an overall increased cerebral blood flow (27). They concluded from 8 small studies ( $n=5-36$ ) containing a total of 153 preterm infants, that the increase in CBF was greater in hypotensive than in normotensive preterm infants. This effect was not repeated in newborn piglets, in which dopamine neither increased $\mathrm{CO}$ nor cerebral blood flow (28). Using NIRS as a method to assess cerebral perfusion in 71 preterm infants without a PDA, a modest increase in cerebral oxygen saturation was seen, both after volume and after dopamine administration (29). Volume administration did not alter cerebral oxygen extraction in a small population of 
preterm infants with clinical signs of poor perfusion (30). The previously mentioned meta-analysis showed no statistically significant differences in adverse neurological outcome between dopamine and dobutamine (three studies; $N=118 ; r=-0.13$; $95 \% \mathrm{CI}=-0.31$ to 0.059$)$ (27).

\section{ADRENALINE AND NA}

Adrenaline is typically used as a second or third line agent in the management of hypotension (2). One RCT compared adrenaline to dopamine in preterm infants $<32$ weeks gestation with low BP. MBP showed a significant increase from baseline throughout the first $96 \mathrm{~h}$ with no differences between groups but adrenaline caused a greater increase in HR and glucose levels more likely to need insulin. They also had higher plasma lactate and lower bicarbonate and base excess values (31). This increase in serum lactate may limit the use of sequential serum lactate measurements to monitor the changes in the perfusion status. As mentioned previously, both low/moderate-dose dopamine and low-dose adrenaline increased cerebral perfusion, as indicated by the increase in both CBV and HbD measured by NIRS (20).

Noradrenaline is a naturally occurring sympathomimetic amine which exerts its cardiogenic effects through activation of $\alpha$ - and $\beta$-adrenoceptors. NA poorly stimulates the vascular $\beta$-adrenoceptors and has a greater effect on peripheral vascular resistance, making it potentially useful in profound hypotension and septic shock (32). Rios et al. examined trends in treatment of neonatal hypotension and found that NA was used in $0.6 \%$ of admissions (33). To date, there are no RCTs assessing the efficacy of NA in neonatal cardiovascular compromise, and the available evidence is predominantly from observational trials. Concerns around NA's potentially potent vasoconstrictor effect has resulted in limited use in preterm infants as it could lead to decreased CO and as a consequence poor tissue perfusion $(34,35)$. Liem retrospectively examined the use of NA in babies born 29-39 weeks gestation. NA succeeded in increasing BP in all babies with hypotension but half required another agent to achieve normotension (36). Rowcliff et al. retrospectively examined the use of NA in infants born less than 32 weeks gestation and found it was effective in increasing MBP. Although tachycardia could be a side effect, no other adverse effects were identified (37). Barrington et al. report the effects of NA in 30 preterm infants with septic shock, highlighting an increase in MBP and urine output following administration (38).

In adults and older children with septic shock, NA is the inotrope of choice due to the presence of low SVR (39). NA administration was also associated with increased urine output and decreased lactate suggesting an improvement in cardiac function and tissue perfusion (40). Derleth used NA in 29 infants born between 22 and 38 weeks gestation with septic shock and found less incidence of PVL in those treated with NA suggesting that despite its vasoconstrictor properties, NA succeeds in maintaining a steady cerebral and myocardial blood flow (41).

Animal studies have shown that NA increases SVR and pulmonary blood flow and therefore improves outcome in pulmonary hypertension (42). Tourneux et al. examined this effect in infants born $>35$ weeks gestation with PPHN and demonstrated improved lung and cardiac function (43). A recent adult study found NA was associated with more enterocyte damage, which might be an important factor to consider in preterm infants (44).

\section{VASOPRESSIN}

Arginine vasopressin (AVP) is a naturally occurring neuropeptide secreted by the posterior pituitary gland. AVP has little or no inotropic or chronotropic effect, instead it exerts its actions on the vasculature $\mathrm{V} 1$ receptors resulting in arterial vasoconstriction and the $\mathrm{V} 2$ receptors of the renal tubule leading to reabsorption of renal free water. The majority of our evidence in preterm infants is from observational studies in refractory hypotension where administration of vasopressin results in an improvement in MBP, urinary output and HR without increasing lactate (45-51). Rios and Kaiser compared vasopressin to dopamine for treatment of hypotension in extremely low birth weight infants (52). Both were shown to be effective in increasing systemic BP, but vasopressin was associated with a reduction in $\mathrm{PaCO}_{2}$, surfactant use, and tachycardia.

Adult studies have demonstrated a reduced level of plasma vasopressin in patients with septic shock (53). This depletion of vasopressin is also evident in pediatric patients, in which small doses of vasopressin resulted in improved systemic BP and urine output $(54,55)$. Meyer et al. compared response to vasopressin in three infants with septic shock to three infants with non-septic shock. While vasopressin resulted in increased BP and urine output in both groups, the results were transient in the non-septic shock infants. Septic shock infants had a reduced HR and lactate level whereas the opposite occurred in the non-septic shock group (56). Many studies note a decrease in requirement of other inotropic agents following initiation of vasopressin to maintain/ increase BP $(47,55)$. Vasopressin has also been shown to increase the sensitivity of vasculature to NA (57).

A potential side effect is poor end organ perfusion $(58,59)$. However, the majority of studies involving vasopressin document its use in refractory hypotension or septic shock in which end organ involvement is often present before initiation (60). There are no data regarding its effect on $\mathrm{CO}$ and cerebral blood flow in preterm infants.

Vasopressin has potential benefit in the treatment of PPHN. In animal studies, vasopressin results in the reduction of pulmonary arterial pressures and the pulmonary:systemic ratio (61). One small observational study in 10 infants with PPHN found that administration of vasopressin resulted in improved oxygenation, $\mathrm{BP}$, urine output, and a reduced iNO requirement (62). Similar findings were noted in patients with congenital diaphragmatic hernias where vasopressin also resulted in improved left ventricular function and oxygenation index (63). The role of vasopressin in the management of circulatory instability in preterm infants remains to be determined.

\section{MILRINONE}

Milrinone is a selective phosphodiesterase III inhibitor in cardiac myocytes and vascular smooth muscle. It has potent vasodilator and inotropic effects leading to a reduction in afterload by decreasing pulmonary vascular resistance (64-66). Milrinone is excreted 
by the kidneys with little or no metabolism (67), therefore, plasma concentration largely depends on renal function. Paradisis et al. demonstrated a longer half-life in preterms (68) and Giaccone et al. found newborns with PPHN had reduced clearance (69).

Animal studies have demonstrated an improvement in right ventricular function and pulmonary vascular resistance $(70,71)$. These findings are consistent with studies involving children post-cardiac surgery $(64,72)$. However, the cAMP levels are decreased in the newborn myocardium, thus newborns may be less sensitive to the effect of milrinone $(73,74)$.

Paradisis conducted one of the few RCTs comparing an agent to placebo in preterm infants (75). Ninety infants born $<30$ weeks gestation were randomized to either milrinone or placebo. They showed no significant difference in SVC flow between the two groups. Jain et al. utilized targeted neonatal echocardiography to measure LVO in preterm infants post PDA ligation. Babies with $\mathrm{LVO}<200 \mathrm{ml} / \mathrm{kg} / \mathrm{min}$ received IV milrinone, and this group was compared with a historic cohort of babies with the same echocardiographic findings post ligation. Those that received milrinone had significantly lower ventilation failure rates, oxygenation failure, and need for inotropic support or steroids, suggesting improved cardiovascular stability (76). Previous studies have advised caution with administration of milrinone as it transiently reduced $\operatorname{MBP}(77,78)$ although little is mentioned on end organ perfusion. Paradisis found significantly lower MBP and a higher $\mathrm{HR}$ at 7 and $10 \mathrm{~h}$ compared with placebo but no significant difference in hypotension (defined as an MBP $<24 \mathrm{mmHg}$ ). It is important to highlight that this study enrolled all babies at risk of low SVC flow as opposed to babies with established hypotension or low-flow states.

Due to its effect on PVR, it may have a useful role in the treatment of PPHN. Samiee-Zafarghandy et al. looked at milrinone use in Neonatal Intensive Care Units (NICU) in North America (79). Milrinone was used in $0.4 \%$ of infants, and the main indication for use (42\%) was PPHN. There are a number of observational studies regarding its use in $\mathrm{PPHN}(77,78,80,81)$. Additional use of milrinone resulted in a reduction in oxygenation index and mean airway pressure. In babies with iNO resistant PPHN, milrinone resulted in improved $\mathrm{LVO}, \mathrm{RVO}$, and ultimately a reduction in iNO requirement (82). RCTs in older children with septic shock demonstrated an improved CO post-milrinone administration (83); however, such studies are lacking in preterm infants.

\section{PRACTICAL ADMINISTRATION CHALLENGES}

In addition to the pharmacodynamics, pharmacokinetics, and pharmacogenetics of inotrope use in preterm infants, delivery kinetics play an important role and must be considered when observing effects. This is especially the case in low-flow rate continuous IV drugs, such as vasoactive drugs for preterm infants, where flow rates of $0.1-1 \mathrm{ml} / \mathrm{h}$ are not uncommon (84). These very low-flow rates combined with relatively significant dead space volumes lead to longer time to onset and steady state of intended doses, and therefore unintended highly variable and unpredictable doses may occur after dosing changes (85). The longer duration for the actual intended dose to be delivered, for drugs with narrow therapeutic indices, can result in significant, unrecognized, and potentially hazardous situations (84).

Several non-patient-specific factors have been studied that might influence this flow rate variability during low-flow rates, which are summarized to the set flow rate, hydrostatic pressure changes and compliance of the complete IV administration system "from pump to patient," and type of substances administered (86).

\section{WHAT IS NEXT?}

Despite 50 years of use, we still have little evidence regarding end organ perfusion and outcome of the various drugs used for both

TABLE 1 | Randomized control trials and measurement of end organ perfusion.

\begin{tabular}{|c|c|c|c|c|c|c|c|c|c|c|}
\hline RCT & Agents & $\begin{array}{c}\text { No. } \\
\text { enrolled }\end{array}$ & $\begin{array}{c}\text { Gestation } \\
\text { (weeks)/birth } \\
\text { weight (g) }\end{array}$ & LVO & RVO & $\begin{array}{l}\text { SVC } \\
\text { flow }\end{array}$ & $\begin{array}{c}\text { Cerebral } \\
\text { perfusion/ } \\
\text { blood flow }\end{array}$ & $\begin{array}{c}\text { GI } \\
\text { Perfusion }\end{array}$ & $\begin{array}{l}\text { Urine } \\
\text { output }\end{array}$ & Lactate \\
\hline Roze et al. (8) & Dop versus Dob & 20 & $<32$ & $x$ & & & & & & \\
\hline Greenough et al. (9) & Dop versus Dob & 40 & $<34$ & & & & & & & \\
\hline Klarr et al. (10) & Dop versus Dob & 63 & $\leq 34$ & & & & & & $x$ & \\
\hline Osborn et al. (16) & Dop versus Dob & 42 & $<30$ & & $x$ & $x$ & & & & \\
\hline Chatterjee et al. (92) & Dop versus Dob & 20 & $<32$ & $x$ & $x$ & & & & & \\
\hline Hentschel et al. (93) & Dop versus Dob & 20 & $25-36$ & & & & & $x$ & & \\
\hline Ruelas-Orozco et al. (94) & Dop versus Dob & 66 & $1,000-1,500$ & & & & & & & \\
\hline Gill et al. (95) & Dop versus volume & 39 & $<1,501$ & & & & & & & \\
\hline Lundstrøm et al. (18) & Dop versus volume & 36 & $<33$ & $x$ & & & $x$ & & & \\
\hline Bravo et al. (17) & Dob versus placebo & 127 & $<31$ & & & $x$ & $x$ & & & $x$ \\
\hline Cuevas et al. (96) & Dop versus placebo & 49 & $700-2,000$ & & & & & & $x$ & $x$ \\
\hline Pellicer et al. (20) & Dop versus Adr & 60 & $<32$ & & & & $x$ & & $x$ & $x$ \\
\hline \multicolumn{11}{|l|}{ Valverde et al. (31) } \\
\hline Phillipos et al. (97) & Dop versus Adr & 20 & $>1,750$ & $x$ & $x$ & & & & & \\
\hline Rios and Kaiser (52) & Dop versus vasopressin & 20 & $\leq 30$ & & & & & & $x$ & $x$ \\
\hline Paradisis et al. (75) & Milrinone versus placebo & 90 & $<30$ & & $x$ & $x$ & $x$ & & & \\
\hline
\end{tabular}

$x$, outcome has been reported; LVO, left ventricular output; RVO, right ventricular output; SVC, superior vena cava; Gl, gastrointestinal; Dop, dopamine; Dob, dobutamine; Adr, adrenaline. 
hypotension and low-flow states in preterm infants. It remains unclear whether cerebral perfusion is increased, unaltered, or reduced with any inotrope use. The effects are most likely mediated by alterations in systemic BP, pulmonary vascular resistance, a direct effect on cerebral vasculature, altered cerebrovascular autoregulation, or a combination of all of the above. Utilization of more objective assessment methods may allow us to gain better insight into these effects (87).

Conducting trials of inotropes in preterm infants has proven challenging on a number of fronts. The majority of the RCTs to date have been conducted in the 1990s with few of these reporting clinically important end points (Table 1). Over the last 10 years, improvements in perinatal care such as antenatal steroid exposure and changes in ventilation management have seen a reduction in the incidence of low BP in preterm infants. Achieving timely informed consent has proved problematic, and as such enrollment has been difficult resulting in very few recent trials to inform the neonatal community. Two small pilot trials have been conducted comparing dopamine to vasopressin (20 infants) and dobutamine to placebo (28 infants). A recent randomized trial highlighted practical challenges, where 10 newborns from a potential population of 127 babies were enrolled across 16 sites $(88,89)$. A recent trial of cardiovascular compromises again highlighted challenges in enrollment in trials of cardiovascular support (90). It is clear that it is proving difficult to perform studies that require enrollment within a short-time window when newborn infants are unstable and often require prompt intervention (91). Until such issues are

\section{REFERENCES}

1. Giesinger RE, McNamara PJ. Hemodynamic instability in the critically ill neonate: an approach to cardiovascular support based on disease pathophysiology. Semin Perinatol (2016) 40(3):174-88. doi:10.1053/j.semperi.2015.12.005

2. Stranak Z, Semberova J, Barrington K, O’Donnell C, Marlow N, Naulaers G, et al. International survey on diagnosis and management of hypotension in extremely preterm babies. Eur JPediatr (2014) 173(6):793-8. doi:10.1007/ s00431-013-2251-9

3. Ounissi M, Benkirane A, Dempsey E, Soares R, Jullien V, Pons G, et al. A review of potential pharmacogenetic effects on catecholamine responses. Drug Metab Rev (2015) 47(4):558-64. doi:10.3109/03602532.2015.1102932

4. Dempsey EM. Under pressure to treat? Arch Dis Child Fetal Neonatal Ed (2015) 100(5):F380-1. doi:10.1136/archdischild-2015-308667

5. Gupta S, Donn SM, editors. Neonatal hypotension: Dopamine or dobutamine? Seminars in Fetal and Neonatal Medicine. Elsevier (2014) 19(1):54-9.

6. Noori S, Seri I. Neonatal blood pressure support: the use of inotropes, lusitropes, and other vasopressor agents. Clin Perinatol (2012) 39(1):221-38. doi:10.1016/j.clp.2011.12.010

7. Sehgal A. Haemodynamically unstable preterm infant: an unresolved management conundrum. Eur J Pediatr (2011) 170(10):1237. doi:10.1007/ s00431-011-1435-4

8. Roze JC, Tohier C, Maingueneau C, Lefevre M, Mouzard A. Response to dobutamine and dopamine in the hypotensive very preterm infant. Arch Dis Child (1993) 69(1 Spec No):59-63. doi:10.1136/adc.69.1_Spec_No.59

9. Greenough A, Emery E. Randomized trial comparing dopamine and dobutamine in preterm infants. Eur J Pediatr (1993) 152(11):925-7. doi:10.1007/ BF01957532

10. Klarr JM, Faix RG, Pryce CJ, Bhatt-Mehta V. Randomized, blind trial of dopamine versus dobutamine for treatment of hypotension in preterm infants with respiratory distress syndrome. J Pediatr (1994) 125(1):117-22. doi:10.1016/ S0022-3476(94)70137-7 addressed, we will continue to utilize agents that may be of no benefit, or potentially have adverse consequences. Institutional review boards, regulatory authorities, funding agencies, and parental organizations need to be aware of these challenges, and an international approach to the problem is required. The recently established International Neonatal Consortium may have a very important role to play in highlighting these challenges and facilitating the conduct of high quality trials of investigational medicinal products, in particular inotropes, in the next number of years.

\section{AUTHOR CONTRIBUTIONS}

All the authors have contributed by writing parts of the first draft, reviewing and adjusting the manuscript to its current form. All the authors agree with the final version of the article.

\section{FUNDING}

This work was supported by a Science Foundation Ireland Research Centre Award (INFANT-12/RC/2272) and the EU FP7/ 2007-2013 under grant agreement no. 260777 (The HIP Trial).

\section{SUPPLEMENTARY MATERIAL}

The Supplementary Material for this article can be found online at https://www.frontiersin.org/articles/10.3389/fped.2018.00088/ full\#supplementary-material.
11. Padbury JF, Agata Y, Baylen BG, Ludlow JK, Polk DH, Goldblatt E, et al. Dopamine pharmacokinetics in critically ill newborn infants. J Pediatr (1987) 110(2):293-8. doi:10.1016/S0022-3476(87)80176-2

12. Stopfkuchen H, Racke K, Schwörer H, Queisser-Luft A, Vogel K. Effects of dopamine infusion on plasma catecholamines in preterm and term newborn infants. Eur J Pediatr (1991) 150(7):503-6. doi:10.1007/BF01958433

13. Mehandru PL, Assel BG, Nuamah IF, Fanaroff AA, Kalhan SC. Catecholamine response at birth in preterm newborns. Neonatology (1993) 64(2-3):82-8. doi:10.1159/000243975

14. Johansson S, Norman M, Legnevall L, Dalmaz Y, Lagercrantz H, Vanpée M. Increased catecholamines and heart rate in children with low birth weight: perinatal contributions to sympathoadrenal overactivity. J Intern Med (2007) 261(5):480-7. doi:10.1111/j.1365-2796.2007.01776.x

15. Subhedar NV, Shaw NJ. Dopamine versus dobutamine for hypotensive preterm infants. Cochrane Database Syst Rev (2003) (3):Cd001242 doi:10.1002/14651858.CD001242.

16. Osborn D, Evans N, Kluckow M. Randomized trial of dobutamine versus dopamine in preterm infants with low systemic blood flow. J Pediatr (2002) 140(2):183-91. doi:10.1067/mpd.2002.120834

17. Bravo MC, Lopez-Ortego P, Sanchez L, Riera J, Madero R, Cabanas F, et al. Randomized, placebo-controlled trial of dobutamine for low superior vena cava flow in infants. J Pediatr (2015) 167(3):el-2. doi:10.1016/j.jpeds.2015.05.037

18. Lundstrøm K, Pryds O, Greisen G. The haemodynamic effects of dopamine and volume expansion in sick preterm infants. Early Hum Dev (2000) 57(2):157-63. doi:10.1016/S0378-3782(00)00048-7

19. Gleason CA, Robinson R, Harris AP, Mayock DE, Traystman RJ. Cerebrovascular effects of intravenous dopamine infusions in fetal sheep. J Appl Physiol (2002) 92(2):717-24. doi:10.1152/japplphysiol.00600.2001

20. Pellicer A, Valverde E, Elorza MD, Madero R, Gaya F, Quero J, et al. Cardiovascular support for low birth weight infants and cerebral hemodynamics: a randomized, blinded, clinical trial. Pediatrics (2005) 115(6):1501-12. doi:10.1542/peds.2004-1396 
21. Clark S, Yoxall C, Subhedar N. Right ventricular performance in hypotensive preterm neonates treated with dopamine. Pediatr Cardiol (2002) 23(2):167-70. doi:10.1007/s00246-001-0041-z

22. Saini SS, Kumar P, Kumar RM. Hemodynamic changes in preterm neonates with septic shock: a prospective observational study. Pediatr Crit Care Med (2014) 15(5):443-50. doi:10.1097/PCC.0000000000000115

23. Liet J-M, Boscher C, Gras-Leguen C, Gournay V, Debillon T, Rozé J-C. Dopamine effects on pulmonary artery pressure in hypotensive preterm infants with patent ductus arteriosus. J Pediatr (2002) 140(3):373-5. doi:10.1067/mpd.2002.123100

24. Seri I, Abbasi S, Wood DC, Gerdes JS. Regional hemodynamic effects of dopamine in the sick preterm neonate. JPediatr (1998) 133(6):728-34. doi:10.1016/S0022-3476(98)70141-6

25. Wong FY, Barfield CP, Horne RS, Walker AM. Dopamine therapy promotes cerebral flow-metabolism coupling in preterm infants. Intensive Care Med (2009) 35(10):1777-82. doi:10.1007/s00134-009-1602-5

26. Eriksen VR, Hahn GH, Greisen G. Dopamine therapy is associated with impaired cerebral autoregulation in preterm infants. Acta Paediatr (2014) 103(12):1221-6. doi:10.1111/apa.12817

27. Sassano-Higgins S, Friedlich P, Seri I. A meta-analysis of dopamine use in hypotensive preterm infants: blood pressure and cerebral hemodynamics. J Perinatol (2011) 31(10):647-55. doi:10.1038/jp.2011.2

28. Eiby YA, Shrimpton NY, Wright IM, Lumbers ER, Colditz PB, Duncombe GJ, et al. Inotropes do not increase cardiac output or cerebral blood flow in preterm piglets. Pediatr Res (2016) 80(6):870-9. doi:10.1038/pr.2016.156

29. Bonestroo HJ, Lemmers PM, Baerts W, van Bel F. Effect of antihypotensive treatment on cerebral oxygenation of preterm infants without PDA. Pediatrics (2011) 128(6):e1502-10. doi:10.1542/peds.2010-3791

30. Kooi EM, Van Der Laan ME, Verhagen EA, Van Braeckel KN, Bos AF. Volume expansion does not alter cerebral tissue oxygen extraction in preterm infants with clinical signs of poor perfusion. Neonatology (2013) 103(4):308-14. doi:10.1159/000346383

31. Valverde E, Pellicer A, Madero R, Elorza D, Quero J, Cabanas F. Dopamine versus epinephrine for cardiovascular support in low birth weight infants: analysis of systemic effects and neonatal clinical outcomes. Pediatrics (2006) 117(6):e1213-22. doi:10.1542/peds.2005-2108

32. Seri I. Circulatory support of the sick preterm infant. Semin Neonatol (2001) 6(1):85-95. doi:10.1053/siny.2000.0034

33. Rios DR, Moffett BS, Kaiser JR. Trends in pharmacotherapy for neonatal hypotension. J Pediatr (2014) 165(4):697-701.e1. doi:10.1016/j.jpeds.2014.06.009

34. Richer M, Robert S, Lebel M. Renal hemodynamics during norepinephrine and low-dose dopamine infusions in man. Crit Care Med (1996) 24(7):1150-6. doi:10.1097/00003246-199607000-00014

35. Mills LC, Moyer JH, Handley CA. Effects of various sympathicomimetic drugs on renal hemodynamics in normotensive and hypotensive dogs. Am J Physiol (1960) 198:1279-83.

36. vanBalen T, deBoode WP, Liem KD. Norepinephrine: Effective in neonatal Hypotension? Arch. Dis. Child. (2008) 93(Suppl 2): pw451.

37. Rowcliff K, de Waal K, Mohamed AL, Chaudhari T. Noradrenaline in preterm infants with cardiovascular compromise. Eur J Pediatr (2016) 175(12):196773. doi:10.1007/s00431-016-2794-7

38. Rizk MY, Lapointe A, Lefebvre F, Barrington KJ. Norepinephrine infusion improves haemodynamics in the preterm infants during septic shock. Acta Paediatr (2018) 107(3):408-13. doi:10.1111/apa.14112

39. Dellinger RP, Levy MM, Rhodes A, Annane D, Gerlach H, Opal SM, et al. Surviving sepsis campaign: international guidelines for management of severe sepsis and septic shock: 2012. Crit Care Med (2013) 41(2):580-637. doi:10.1097/CCM.0b013e31827e83af

40. Tourneux P, Rakza T, Abazine A, Krim G, Storme L. Noradrenaline for management of septic shock refractory to fluid loading and dopamine or dobutamine in full-term newborn infants. Acta Paediatr (2008) 97(2):177-80. doi:10.1111/j.1651-2227.2007.00601.x

41. Derleth DP. Clinical experience with norepinephrine (NE) infusions in critically Ill newborns. 856. Pediatr Res (1997) 41:145. doi:10.1203/00006450-199704001-00877

42. Jaillard S, Elbaz F, Bresson-Just S, Riou Y, Houfflin-Debarge V, Rakza T, et al. Pulmonary vasodilator effects of norepinephrine during the development of chronic pulmonary hypertension in neonatal lambs. Br J Anaesth (2004) 93(6):818-24. doi:10.1093/bja/aeh278
43. Tourneux P, Rakza T, Bouissou A, Krim G, Storme L. Pulmonary circulatory effects of norepinephrine in newborn infants with persistent pulmonary hypertension. J Pediatr (2008) 153(3):345-9. doi:10.1016/j.jpeds.2008.03.007

44. Habes QLM, van Ede L, Gerretsen J, Kox M, Pickkers P. Norepinephrine contributes to enterocyte damage in septic shock patients; a prospective cohort study. Shock (2018) 49(2):137-43. doi:10.1097/SHK.0000000000000955

45. Ni M, Kaiser JR, Moffett BS, Rhee CJ, Placencia J, Dinh KL, et al. Use of vasopressin in neonatal intensive care unit patients with hypotension. J Pediatr Pharmacol Ther (2017) 22(6):430-5. doi:10.5863/1551-6776-22.6.430

46. Meyer S, Gortner L, McGuire W, Baghai A, Gottschling S. Vasopressin in catecholamine-refractory shock in children. Anaesthesia (2008) 63(3):228-34. doi:10.1111/j.1365-2044.2007.05317.x

47. Lechner E, Hofer A, Mair R, Moosbauer W, Sames-Dolzer E, Tulzer G. Arginine-vasopressin in neonates with vasodilatory shock after cardiopulmonary bypass. Eur J Pediatr (2007) 166(12):1221-7. doi:10.1007/ s00431-006-0400-0

48. Liedel JL, Meadow W, Nachman J, Koogler T, Kahana MD. Use of vasopressin in refractory hypotension in children with vasodilatory shock: five cases and a review of the literature. Pediatr Crit Care Med (2002) 3(1):15-8. doi:10.1097/00130478-200201000-00004

49. Vasudevan A, Lodha R, Kabra S. Vasopressin infusion in children with catecholamine-resistant septic shock. Acta Paediatr (2005) 94(3):380-3. doi:10.11 11/j.1651-2227.2005.tb03086.x

50. Lechner E, Dickerson H, Fraser C, Chang A. Vasodilatory shock after surgery for aortic valve endocarditis: use of low-dose vasopressin. Pediatr Cardiol (2004) 25(5):558-61. doi:10.1007/s00246-003-0544-x

51. Bidegain M, Greenberg R, Simmons C, Dang C, Cotten CM, Smith PB. Vasopressin for refractory hypotension in extremely low birth weight infants. J Pediatr (2010) 157(3):502-4. doi:10.1016/j.jpeds.2010.04.038

52. Rios DR, Kaiser JR. Vasopressin versus dopamine for treatment of hypotension in extremely low birth weight infants: a randomized, blinded pilot study. J Pediatr (2015) 166(4):850-5. doi:10.1016/j.jpeds.2014.12.027

53. Landry DW, Levin HR, Gallant EM, Ashton RC, Seo S, D'Alessandro D, et al. Vasopressin deficiency contributes to the vasodilation of septic shock. Circulation (1997) 95(5):1122-5. doi:10.1161/01.CIR.95.5.1122

54. Masutani S, Senzaki H, Ishido H, Taketazu M, Matsunaga T, Kobayashi T, et al. Vasopressin in the treatment of vasodilatory shock in children. Pediatr int (2005) 47(2):132-6. doi:10.1111/j.1442-200x.2005.02043.x

55. Rosenzweig EB, Starc TJ, Chen JM, Cullinane S, Timchak DM, Gersony $\mathrm{WM}$, et al. Intravenous arginine-vasopressin in children with vasodilatory shock after cardiac surgery. Circulation (1999) 100(Suppl 2):II-182-Ii-6. doi:10.1161/01.CIR.100.suppl_2.II-182

56. Meyer S, Gottschling S, Baghai A, Wurm D, Gortner L. Arginine-vasopressin in catecholamine-refractory septic versus non-septic shock in extremely low birth weight infants with acute renal injury. Crit Care (2006) 10(3):R71. doi:10.1186/cc4917

57. Noguera I, Medina P, Segarra G, Martinez M, Aldasoro M, Vila J, et al. Potentiation by vasopressin of adrenergic vasoconstriction in the rat isolated mesenteric artery. Br J Pharmacol (1997) 122(3):431-8. doi:10.1038/ sj.bjp. 0701397

58. Berg RA. A long-acting vasopressin analog for septic shock: brilliant idea or dangerous folly? Pediatr Crit Care Med (2004) 5(2):188-9. doi:10.1097/01. PCC.0000121301.62216.0D

59. Wilson SJ, Mehta SS, Bellamy MC. The safety and efficacy of the use of vasopressin in sepsis and septic shock. Expert Opin Drug Saf (2005) 4(6):1027-39. doi:10.1517/14740338.4.6.1027

60. Efrati O, Modan-Moses D, Vardi A, Matok I, Bazilay Z, Paret G. Intravenous arginine vasopressin in critically ill children: is it beneficial? Shock (2004) 22(3):213-7. doi:10.1097/01.shk.0000135258.52194.78

61. Evora PR, Pearson PJ, Schaff HV. Arginine vasopressin induces endothelium-dependent vasodilatation of the pulmonary artery: V1-receptor-mediated production of nitric oxide. Chest (1993) 103(4):1241-5. doi:10.1378/ chest.103.4.1241

62. Mohamed A, Nasef N, Shah V, McNamara PJ. Vasopressin as a rescue therapy for refractory pulmonary hypertension in neonates: case series. Pediatr Crit Care Med (2014) 15(2):148-54. doi:10.1097/PCC.0b013e31829f5fce

63. Acker SN, Kinsella JP, Abman SH, Gien J. Vasopressin improves hemodynamic status in infants with congenital diaphragmatic hernia. J Pediatr (2014) 165(1):53.-58. doi:10.1016/j.jpeds.2014.03.059 
64. Chang AC, Atz AM, Wernovsky G, Burke RP, Wessel DL. Milrinone: systemic and pulmonary hemodynamic effects in neonates after cardiac surgery. Crit Care Med (1995) 23(11):1907-14. doi:10.1097/00003246-199511000-00018

65. Beavo JA. Cyclic nucleotide phosphodiesterases: functional implications of multiple isoforms. Physiol Rev (1995) 75(4):725-48. doi:10.1152/physrev. 1995.75.4.725

66. Silver PJ, Harris AL, Canniff PC, Lepore RE, Bentley RG, Hamel LT, et al. Phosphodiesterase isozyme inhibition, activation of the cAMP system, and positive inotropy mediated by milrinone in isolated guinea pig cardiac muscle. J Cardiovasc Pharmacol (1989) 13(4):530-40. doi:10.1097/00005344198913040-00004

67. Gist KM, Mizuno T, Goldstein SL, Vinks A. Retrospective evaluation of milrinone pharmacokinetics in children with kidney injury. Ther Drug Monit (2015) 37(6):792-6. doi:10.1097/FTD.0000000000000214

68. Paradisis M, Jiang X, McLachlan AJ, Evans N, Kluckow M, Osborn D. Population pharmacokinetics and dosing regimen design of milrinone in preterm infants. Arc Dis Child Fetal Neonatal Ed (2007) 92(3):F204-9. doi:10.1136/adc.2005.092817

69. Giaccone A, Zuppa AF, Sood B, Cohen MS, O’Byrne ML, Moorthy G, et al. Milrinone pharmacokinetics and pharmacodynamics in neonates with persistent pulmonary hypertension of the newborn. Am J Perinatol (2017) 34(8):749-58. doi:10.1055/s-0036-1597996

70. Chen EP, Bittner HB, Davis RD, Van Trigt P. Milrinone improves pulmonary hemodynamics and right ventricular function in chronic pulmonary hypertension. Ann Thorac Surg (1997) 63(3):814-21. doi:10.1016/ S0003-4975(97)00011-8

71. Chen EP, Bittner HB, Davis RD, Van Trigt P. Hemodynamic and inotropic effects of milrinone after heart transplantation in the setting of recipient pulmonary hypertension. J Heart Lung Transplant (1998) 17(7):669-78.

72. Bianchi MO, Cheung P-Y, Phillipos E, Aranha-Netto A, Joynt C. The effect of milrinone on splanchnic and cerebral perfusion in infants with congenital heart disease prior to surgery: an observational study. Shock (2015) 44(2):115-20. doi:10.1097/SHK.0000000000000388

73. Oquist NL, Strada SJ, Artman M. Inotropic responses to selective (RO 20-1724 and SQ 65, 442) and nonselective (trequinsin) inhibitors of cyclic AMP-specific class IV phosphodiesterase in newborn, immature, and adult rabbit myocardium. Pediatr Res (1992) 31(3):300. doi:10.1203/00006450199203000-00023

74. Ogawa S-I, Nakanishi T, Kamata K, Takao A. Effect of milrinone on myocardial mechanical function and cyclic AMP content in the fetal rabbit. Pediatr Res (1987) 22(3):282-5. doi:10.1203/00006450-198709000-00009

75. Paradisis M, Evans N, Kluckow M, Osborn D. Randomized trial of milrinone versus placebo for prevention of low systemic blood flow in very preterm infants. J Pediatr (2009) 154(2):189-95. doi:10.1016/j.jpeds.2008.07.059

76. Jain A, Sahni M, El-Khuffash A, Khadawardi E, Sehgal A, McNamara PJ. Use of targeted neonatal echocardiography to prevent postoperative cardiorespiratory instability after patent ductus arteriosus ligation. J Pediatr (2012) 160(4):584.e-9.e. doi:10.1016/j.jpeds.2011.09.027

77. James A, Bee C, Corcoran J, McNamara P, Franklin O, El-Khuffash A. Treatment of premature infants with pulmonary hypertension and right ventricular dysfunction with milrinone: a case series. JPerinatol (2015) 35(4):268-73. doi:10.1038/jp.2014.208

78. McNamara PJ, Shivananda SP, Sahni M, Freeman D, Taddio A. Pharmacology of milrinone in neonates with persistent pulmonary hypertension of the newborn and suboptimal response to inhaled nitric oxide. Pediatr Crit Care Med (2013) 14(1):74-84. doi:10.1097/PCC.0b013e31824ea2cd

79. Samiee-Zafarghandy S, Raman SR, van den Anker JN, McHutchison K, Hornik $\mathrm{CP}$, Clark RH, et al. Safety of milrinone use in neonatal intensive care units. Early Hum Dev (2015) 91(1):31-5. doi:10.1016/j.earlhumdev.2014.10.007

80. McNamara PJ, Laique F, Muang-In S, Whyte HE. Milrinone improves oxygenation in neonates with severe persistent pulmonary hypertension of the newborn. J Crit Care (2006) 21(2):217-22. doi:10.1016/j.jcrc.2006.01.001

81. Bassler D, Choong K, McNamara P, Kirpalani H. Neonatal persistent pulmonary hypertension treated with milrinone: four case reports. Neonatology (2006) 89(1):1-5. doi:10.1159/000088192
82. James AT, Corcoran JD, McNamara PJ, Franklin O, El-Khuffash AF. The effect of milrinone on right and left ventricular function when used as a rescue therapy for term infants with pulmonary hypertension. Cardiol Young (2016) 26(1):90-9. doi:10.1017/S1047951114002698

83. Barton P, Garcia J, Kouatli A, Kitchen L, Zorka A, Lindsay C, et al. Hemodynamic effects of iv milrinone lactate in pediatric patients with septic shock: a prospective, double-blinded, randomized, placebo-controlled, interventional study. Chest (1996) 109(5):1302-12. doi:10.1378/chest.109.5.1302

84. Bartels K, Moss DR, Peterfreund RA. An analysis of drug delivery dynamics via a pediatric central venous infusion system: quantification of delays in achieving intended doses. Anesth Analg (2009) 109(4):1156-61. doi:10.1213/ ane.0b013e3181b220c9

85. Sherwin CM, Medlicott NJ, Reith DM, Broadbent RS. Intravenous drug delivery in neonates: lessons learnt. Arch Dis Child (2014) 99(6):590-4. doi:10.1136/archdischild-2013-304887

86. van der Eijk AC, van Rens RM, Dankelman J, Smit BJ. A literature review on flow-rate variability in neonatal IV therapy. Paediatr Anaesth (2013) 23(1):9-21. doi:10.1111/pan.12039

87. Dempsey EM, El-Khuffash AF. Objective cardiovascular assessment in the neonatal intensive care unit. Arch Dis Child Fetal Neonatal Ed (2018) 103(1):F72-7. doi:10.1136/archdischild-2017-313837

88. Batton BJ, Li L, Newman NS, Das A, Watterberg KL, Yoder BA, et al. Feasibility study of early blood pressure management in extremely preterm infants. J Pediatr (2012) 161(1):65-9e1. doi:10.1016/j.jpeds.2012.01.014

89. Vain NE, Barrington KJ. Feasibility of evaluating treatment of early hypotension in extremely low birth weight infants. J Pediatr (2012) 161(1):4-7. doi:10.1016/j.jpeds.2012.02.029

90. Watterberg KL, Fernandez E, Walsh MC, Truog WE, Stoll BJ, Sokol GM, et al. Barriers to enrollment in a randomized controlled trial of hydrocortisone for cardiovascular insufficiency in term and late preterm newborn infants. J Perinatol (2017) 37(11):1220-3. doi:10.1038/jp.2017.131

91. Steinhorn RH, Fineman J, Kusic-Pajic A, Cornelisse P, Gehin M, Nowbakht P, et al. Bosentan as adjunctive therapy for persistent pulmonary hypertension of the newborn: results of the randomized multicenter placebo-controlled exploratory trial. J Pediatr (2016) 177(90-6):e3. doi:10.1016/j.jpeds.2016.06.078

92. Chatterjee A, Bussey M, Leuschen M, Latson L, Hole E, Christian K, et al., editors. The pharmacodynamics of inotropic drugs in premature neonates. Clin Res (1993) 33:206A.

93. Hentschel R, Hensel D, Brune T, Rabe H, Jorch G. Impact on blood pressure and intestinal perfusion of dobutamine or dopamine in hypotensive preterm infants. Neonatology (1995) 68(5):318-24. doi:10.1159/000244252

94. Ruelas-Orozco G, Vargas-Origel A. Assessment of therapy for arterial hypotension in critically ill preterm infants. Am J Perinatol (2000) 17(02):095-100. doi:10.1055/s-2000-9265

95. Gill A, Weindling A. Randomised controlled trial of plasma protein fraction versus dopamine in hypotensive very low birthweight infants. Arch Dis Child (1993) 69(3 Spec No):284-7. doi:10.1136/adc.69.3_Spec_No.284

96. Cuevas L, Yeh TF, John EG, Cuevas D, Plides RS. The effect of low-dose dopamine infusion on cardiopulmonary and renal status in premature newborns with respiratory distlow-dosedrome. Am J Dis Child (1991) 145(7):787-96.

97. Phillipos EZ, Barrington KJ, Robertson MA. Dopamine (D) versus epinephrine (E) for inotropic support in the neonate: a randomized double blinded controlled trial. $\dagger 1414$. Pediatr Res (1996) 39:238. doi:10.1203/00006450199604001-01437

Conflict of Interest Statement: The authors declare that the research was conducted in the absence of any commercial or financial relationships that could be construed as a potential conflict of interest.

Copyright $\odot 2018$ Garvey, Kooi and Dempsey. This is an open-access article distributed under the terms of the Creative Commons Attribution License (CC BY). The use, distribution or reproduction in other forums is permitted, provided the original author(s) and the copyright owner are credited and that the original publication in this journal is cited, in accordance with accepted academic practice. No use, distribution or reproduction is permitted which does not comply with these terms. 